\title{
Exploration on Student-Centered Fermentation Engineering Course by Problems Conducted Teaching
}

\author{
Lijun $\mathrm{Ge}^{1}$, Zhenhong Zhu ${ }^{1}$, Qin $\mathrm{Yu}^{1}$, Haitong $\mathrm{Wan}^{2 *}$ \\ ${ }^{1}$ College of Biological Engineering, Zhejiang Chinese Medical University, Hangzhou, China \\ ${ }^{2}$ Biological and Pharmaceutical Engineering Research Institute, Zhejiang Chinese Medical University, Hangzhou, China \\ Email: "gelijun@zjtcm.net
}

Received October $13^{\text {th }}$, 2012; revised November $15^{\text {th }}$, 2012; accepted November $30^{\text {th }}$, 2012

\begin{abstract}
Based on the feature of Fermentation Engineering Course, Study on student-centered classroom teaching by new teaching modes and methods to stimulate students' learning motivation and develop students' innovating ability. Combines problem based learning (PBL) with case based learning (CBS) teaching methods. In the process of teaching, guiding the students to think actively through questions, and participation in class discussion, courseware, simulation teaching, etc. and guiding students to analyze and solve problems, construction guide classroom teaching model. The results show that the student's initiative, enthusiasm and learning effect were improved obviously. And the way of teaching achieved good teaching results, which not only highlighted the student-centered teaching philosophy, but also learned the advantages of a wide range of teaching methods.
\end{abstract}

Keywords: Student Centered; Fermentation Engineering; Teaching Mode; Problems Conducted Teaching Component

\section{Introduction}

Fermentation engineering course is a strong application, practice of specialized course in the biological engineering professional. It is mass production of the required products process theory and an engineering technology courses, through microbial growth and metabolic activity and modern chemical technology. The content of the course are rich and various, and contains modern biological science and engineering science and technology. In recent years, teaching methods reform, such as insisting inheritance innovation, putting an emphasis on the cross and integration by multi-disciplinary knowledge, and student-centered teaching concept, etc. (Jin, 2009). And it have become one of the main direction of improving the students' practice ability and innovation consciousness training and deepen teaching reform.

In this paper, we try to combine the teaching method of problem-based learning (PBL) (Chen, Sun, \& Xu, 2006). With the teaching method of Case-based study (CBS), and according to the application experience of these teaching methods in fermentation engineering course, discuss these innovative teaching methods reform thinking and ideas of Student-Centered Fermentation Engineering Course (Ni, Tang, \& Han, 2009).

\section{Reform and Adjust of Teaching Contests}

\section{Optimize Course Content and Combining the Specialty Characteristics}

The construction of teaching material is an important part of the construction of course; it's directly related to the innovation of teaching content and the teaching goal of implementation. At present, the textbook series of fermentation engineering course

*Corresponding author. has published more than 10 kinds, and the different versions of textbooks have different emphasis, because of a wide range of fermentation engineering content. Such as "The New Biotechnology” edited by Prof. Jun-Tang Yu (2006) in East China University of Science \& Technology includes two volumes; The first volume pays much attention to introduce the microbial principle, which have many similar contents with Microbiology course; The second volume pays much attention to talk about biochemical separation approach, which have many similar contents with Biochemical separation engineering course. So, shortcomings are the content of the textbook which has obvious repetitiveness of one another when choice of teaching materials. And there is also the similar phenomenon of the repeated content between "The Microbial Project” edited by Prof. Jun-wei Cao (2008) and "The Introduce to Microbial Project" edited by Prof. Bi-Lian Chen (2010). And the content of "Microbial Engineering Process Principle” edited by Prof. Ru-Hua Yao (2005) in South China University of Technology is too focused on antibiotics fermentation unit, but other fermentation process case involves inadequate. So using only a kind of textbook is hard to let students grasp biotechnology all classic fermentation technology content.

In recent years, We set the course is oriented around the fermentation products production of the common unit process modules, and stress on "multifaceted, solid fundamentals, high abilities and qualities" as a new principle of education, through collective classes and teaching research, enhance the quality of preparation.

Now, the "Fermentation Engineering Principle and Technology Application” edited by Prof. Jiang-Long Yu (2011) is used in our college. It elaborates the fermentation engineering common principle and fermentation technology examples respectively. It not only insists on and involves the advantages that 
the other textbook have, but also involves new teaching content. It provides a good platform for construct methods of problems conducted teaching about student-centered fermentation engineering course.

In addition, we appoint a list of reference books such as The New Biotechnology (Yu, Tang, Wu, \& Li, 2006); Fermentation Industry Overview (Li, 2011); Biochemical Separation Engineering (Tan, 2011); Microbial Engineering Process Principle etc (Yao \& Zhou, 2005).

\section{Pay Attention to the Disciplinary Development}

Fermentation engineering is a rapid development of the discipline, the new craft, the new technology, and the new study results are endless. We adjusted old courses and offered new courses to adapt the new circle curriculum reform, based on the teaching material in classroom teaching. And refer to the other related books and domestic and international professional journals. Such as, Response Surface Analysis (RSA) was applied to optimize the culture medium in the culture medium optimal design section, when introducing the principal mechanism of culture medium optimal design. Another example is the promising new technology of oxygen supply on high cell density fermentation, which is applied to solution fermentation; it can greatly improve the transfer efficiency of oxygen and increase fermentation level dramatically.

\section{Teaching Methods of Design on Problems Conducted Teaching}

Teaching method of Problem-based Learning (PBL) is very popular now. It has gradually become a new modern model of classroom teaching (Liu, 2009). Problem-based learning (PBL) is a teaching method which gives priority to student's initiative learning. It may play student's main body role fully, the reassignment study enthusiasm, and promoting the personality of students. But the teaching reform of PBL was only in a primary period in higher education of Chinese medicine. Whether it is appropriate to apply PBL should be based on the specific circumstances of the case, and should not mechanically copy while spreading and applying PBL. So applying PBL in higher medical education is still under exploration.

It has its limitation to some extend. One reason is that PBL lacks systematization of the structure of knowledge. In addition, the cover area of problems to be solved is incomplete for the undergraduate education content, and more likely to have the gaps in student's knowledge. Thus, it's quite necessary for us to adopt flexible problems conducted teaching in the teaching process of the undergraduate education.

Inducing-mode teaching is that students' practical give priority to, teachers guide for auxiliary ( $\mathrm{Li}, 2005)$. It focuses on the integration between the teacher's leading role and the students' main body role. The autonomous learning mode throughout the entire class process, which fully reflect the students' self-advocacy, cooperation, explore learning styles, students cultivate the spirit of innovation.

In Fermentation Engineering Course, we combine the teaching method of problem-based learning (PBL) with the teaching method of case-based study (CBS), and innovating the educational contents, links, and methods according to the characteristic of the course in the teaching practice. And get a good effect by designing teaching steps carefully on.
The classroom teaching model of Problems Conducted Teaching included core problems, the basic problems, openended questions. For example, in the aerobic fermentation case, as follow:

Firstly, we provide "the biosynthetic pathway and metabolic regulation mechanism of citric acid, and how the fermentation conditions affect the accumulation of citric acid" for students as core problem to be discuss.

And then redesign "Medium preparation of citric acid fermentation", "some common characteristics in aerobic fermentation" as the basic problems, Guide Students to summary and conclusion themselves. The purpose of the basic problems is to make students contact theory and fact, summarize and analyze the status, discover the problem, find the reason, and promote the advices and steps.

Finally, we design some open-ended questions for groups with 5 - 6 students to answer and write reports, after consulting the related reference books, the web resources, and the literature published in China and abroad in recent years. For example, the characters and mechanisms of itaconic acid fermentation by Aspergillums; and the characters and mechanisms of acetic acid fermentation by acetic acid bacteria.

\section{Student-Centered Fermentation Engineering Course Practice}

Student-Centered teaching is a universal theme in the field of modern education and is embodies of modern educational concepts. It has important Curriculum and teaching values. It is the key to improvement of teaching quality (Ding, 2007). This course features is that combining teaching with learning, and combining the teachers" leading role with the students' subject role, and not completely hands-off management. The role of teachers is to act as the organizer, the guide, mentoring relationships.

\section{The Student-Centered Class Includes}

Each group of student representative, to explain the problems on fermentation mechanisms, principles, characteristics, conditions. Other groups discuss for minutes at the end of a speech.

After discussion, each group to report on the outcome of the discussions, and other participants to give questions and comments.

The teacher comment on each group' reports, and then summarize with summing up through an analysis of teaching course.

The analysis and evaluation of the final results each group.

\section{Specific Problems of Design in Fermentation Engineering Course as Follows}

The Core Problems:

The types and technical requirements of aerobic fermentation?

The types and technical requirements of anaerobic fermentation?

The types and technical requirements of solid state fermentation?

The types and technical requirements of the liquid fermentation?

The Basic Problems:

The principle of Media preparation? 
The principle of moist heat sterilization?

The types and features of Industrial Microbiology?

The content and methods of the fermentation kinetics?

\section{The Open-Ended Questions:}

The mechanism and features of Yeast alcohol fermentation?

The mechanism and features of citric acid fermentation?

The secondary metabolite of antibiotics fermentation mechanism principle?

In addition, the teaching method was also applied in fermentation engineering experiment in the attempt. From the effects of fermentation engineering experiment, it is better than theory course. The possible reasons are that students involved in the experiment of a single fermentation example have been a level of understanding. The experiment course arrangement followed the related theory course content progress. For example, the citric acid liquid fermentation experiments by Aspergillums. Student's enthusiasm and initiative conscious-ness more strongly than theory course. The traits as following: students' autonomy, good team spirit, strong problem solving and analytical skill in the lab class.

\section{Conclusion}

Through the implementation of the reform of Problems Conducted Teaching, it changed the traditional "Cramming method of teaching”. Combining the problem based learning (PBL) with the case based learning (CBS) teaching methods, which not only can significantly improved the students' enthusiasm and initiative, but also can let students learn more happy. It fully reflects the teaching idea of Student-Centered Fermentation Engineering Course.

In the teaching reform of the process also meet some new problems. Firstly, the teaching mode for teacher put forward the higher requirements. Teachers not only spend a lot of time and energy on setting problem, guiding students before classes; but also have a high the control of the classroom teaching process ability. Secondly, establishing and perfecting the formative evaluation system, and the integration and innovation of ex- periment teaching, which will be faced a new round of the teaching reform to try.

We believe that the "student-centered" fermentation engineering teaching level and quality will gradually improve and perfect, and will provide a good platform of cultivating applied and compound person with the school and teacher's efforts.

\section{REFERENCES}

Cao, J. W., Ma, H. W., \& Zhang, J. Y. (2008). Microbial engineering (pp. 55-59). Beijing: Science Press.

Chen, B. L. (2010). Microbial engineering. Beijing: Science Press.

Chen, Z. Q., Sun, T. Y., \& Xu, D. X. (2006). Explore on the feasibility of problem-based Learning in our country. Medical Journal of $\mathrm{Na}$ tional Defending Forces in Southwest China, 64, 433-435.

Ding, X. J. (2007). Student-centered teaching: The history review and the latest progress. Education Development Research Journals, 12, 53-58.

Jin, H. R. (2009). Creating the new teaching mode of fermentation engineering by study the practice the scientific concept of development. The Science Education Article Collects, 23, 37-38.

Li, D. W. (2005). In higher vocational practical teaching behavior guide the practice of teaching the course and explored. Study and Practice, 6, 34-36.

Li, Y. (2011). Fermentation industry overview. Beijing: China Light Industry Press.

Liu, J. Y. (2009). The application of problem-based learning (PBL) in the British medical education. Foreign Medical Education, 20, 7-10.

Ni, J. L., Tang, X. L., \& Han, Z. Z. (2009). Practice and experience about teaching mode by a series question brought forward taking structure geology as an example. Chinese Geological Education, 12, 143-145.

Tan, T. W. (2011). Biological separation technology. Beijing: Chemical Industry Publication.

Yao, R. H., Zhou, S. S. (2005). Microbial engineering process principle. Guangzhou: South China University of Technology Press.

Yu, J. L. (2011). Fermentation engineering principle and technology applicatio. Beijing: Chemistry Industry Press.

Yu, J. T., Tang, X. X., Wu, X. Y., \& Li, Y. R. (2006). New biotechnology (pp. 114-117). Beijing: Chemistry Industry Press. 